\title{
No technical fix to a political problem
}

\section{THE International Nuclear Fuel Cycle Evaluation ended on 29 February with a plenary session that adopted the reports of all the study groups. Hermann Bondi (right) Chief Scientist at the UK Department of Energy and leader of the British delegation to INFCE, assesses its work}

THE INFCE reports naturally reflect many points of view, yet they were unanimosly agreed. Some countries had suggested 'technical fixes'; some claimed that energy independence was necessary, and that the whole argument about non-proliferation was just a device to keep a vital new technology firmly confined to the most advanced states. But it was agreed that there is no technical fix to the political problem of proliferation. There is no fuel cycle that presents no such risks and dangers. On the other hand the working groups looked closely at the sensitive areas; how they could be made less risky, what could be done to improve their security, and what institutional measures could be evolved which would further increase international re-assurance.

I concentrate on four areas: the availability of nuclear fuel, the economics of the fuel cycles, the risks of proliferation, and the terms and conditions of nuclear supply agreements. Safety and environmental questions were not addressed in any great detail.

INFCE assumes a fairly high rate of growth in nuclear generating capacity. Compared with about $125 \mathrm{GW}$ of capacity today, INFCE projects 850 to $1200 \mathrm{GW}$ in

\section{Background and participants}

INFCE was set up in Washington in October 1977, in response to heated disagreements between states over the nuclear fuel and technology trade. In particular, President Carter had aroused anxiety among developing nations in April that year when he called a halt to the separation and use of plutonium, implying the deferral of reprocessing and confinement to a once-through cycle.

Sixty-six countries took part in the discussions; industrialised and developing; weapons and non-weapons states; East and West; nuclear suppliers and customers; those that had signed the NonProliferation Treaty and those that had not. Five international organisations also took part. The Evaluation was not, however, a negotiation. The Organising Conference set up eight working groups, linked by a Technical Co-ordinating Committee. the non-Communist world in 2000 , and 1800 to $3900 \mathrm{GW}$ in 2025 . With use of the once-through cycle and on its high projection of growth, INFCE concludes that the lifetime uranium requirements of the reactors installed and in operation by 2000 will approach current estimates of known uranium resources ( $5 \mathrm{mTU})$. These figures have been criticised, notably in the US, for being unduly pessimistic about uranium availability.

But the figures are not everything. INFCE rightly stressed that the uncertainties in these forecasts are great not just in the prediction of nuclear demand and of the extent and accessibility of geological reserves of uranium. The uncertainties in the political availability of uranium are greater perhaps than for any other commodity. The message is simple. If countries are to be confident that there will be enough uranium to fuel their reactors over the next 30 to 40 years, acceptable solutions to political and environmental problems limiting the exploitation of uranium must be found, new sources of uranium must be discovered and brought into production, and reactor strategies that conserve uranium must be adopted by at least some of the big users.

The scope for new discoveries of uranium is good. Estimates range from 6.6 to $14.8 \mathrm{mTU}$. If these resources can be discovered, brought into production, and the uranium made available internationally, supply should meet the requirements of INFCE's perhaps more realistic low projection of nuclear growth to beyond 2025. But the extent to which this will happen is uncertain. The more pessimistic a country, and the more dependent it is on uranium imports, the more likely it is to want to move to the early introduction of reactors that conserve uranium, such as advanced thermal reactors and fast reactors.

Fast reactors offer the prospect of nuclear development eventually almost free from uranium supply constraints. So while INFCE does not say that the early introduction of fast reactors is essential on resource grounds, it does illustrate the impact of decisions about reactor strategy - and their timing - on uranium supply and demand. Such decisions, like many in energy policy, depend largely on a country's perception of its need to be

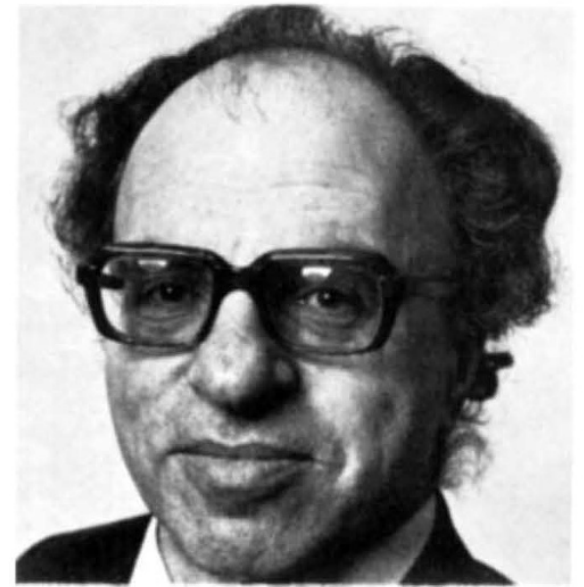

insured against uncertainties in fuel supplies.

In discussions on the economic aspects of the fuel cycles it became clear that considerations vary from country to country. No fuel cycle can be said to have a universal economic advantage over the next few decades. Recycle into light water reactors is of only minor economic advantage, but may offer the benefits of reducing reliance on imported uranium. On the other hand, if the capital and fuel cycle costs of fast reactors can be brought down, fast reactor recycle could offer considerable advantages.

INFCE came to no definite conclusion on when the fast reactor would compete economically with thermal reactors. The uncertainties in the future price of uranium and of fast reactors, and regional variations in uranium supply, mean that countries will take different views about when to proceed from thermal to fast reactors.

Much of INFCE's discussion centred on two related subjects: how the risk and the fear of weapons proliferation can be reduced, and how to make nuclear energy widely and assuredly available.

From the start it was recognised that a decision to construct nuclear weapons is political, and that the misuse of the civil fuel cycle is not the easiest or cheapest route to acquiring them. INFCE was a technical, not a political evaluation. The reports, therefore, look only at the way in which a civil nuclear programme might help a country make a nuclear explosive.

The misuse of fuel cycles that involve the handling of large quantities of weaponsusable material - not just plutonium, but highly enriched uranium (HEU) or uranium 233 - might offer a path. But discussions in the Working Groups and in the TCC showed that comparisons between the proliferation risks of the various fuel cycles were extremely complex. How, for example, does one assess the relative proliferation 